\title{
Computed Tomographic Evaluation of Mediastinal Masses - An Experience at a Tertiary Care Centre in Bareilly, India
}

\author{
Manish Kumar1, Tanuja Sharma², Mayank Jain³, Priyanka Raj ${ }^{4}$, \\ Deeksha Singh ${ }^{5}$, Mohd Talha ${ }^{6}$, Amit Kumar $^{7}$, Lalit Kumar ${ }^{8}$
}

1, 2, 3, 4, 5, 6, 7, 8 Department of Radiodiagnosis, Rohilkhand Medical College and Hospital, Bareilly, Uttar Pradesh, India

\section{ABSTRACT}

\section{BACKGROUND}

Mediastinal lesions are one of the most common lesions of the chest in children and adults. Multidetector computed tomography (MDCT) is the most common investigation done in patients with suspected abnormalities on X-ray. Crosssectional imaging visualises complex anatomy, helps in predicting the tissue of origin, characterises lesions and depicts the extent of involvement of adjacent structures. Complications of mediastinal lesions and emergent conditions, for example, sealed pneumo-mediastinum, tracheoesophageal / pulmonary fistula, a peri-lesional abscess can be well assessed on CECT. The possibility of the lesion as benign or malignant and can be well predicted. Vascular lesions like aneurysms, dissections, and embolism can be evaluated and stable lesions requiring to follow up and unstable lesions requiring emergent treatment are differentiated using MDCT. The objectives of the study were to characterize and identify features pathognomic of specific mediastinal masses on computed tomography and find out diagnostic accuracy of MDCT in mediastinal masses and compare them with pathological results wherever possible.

\section{METHODS}

A prospective study was done in the Department of Radiodiagnosis, Rohilkhand Medical College and hospital, Bareilly for a span of 1 year from November 2018 to October 2019. Our study included 51 patients. Mediastinal lesions were assessed based on size, compartmental localisation, and attenuation and enhancement patterns.

\section{RESULTS}

In our study with 51 patients, 16 lesions were non-neoplastic and 35 were neoplastic lesions. Anterior mediastinal lesions constituted maximum lesions followed by middle and posterior mediastinal lesions. Lymph nodal masses were the commonest lesions out of which 4 cases were tubercular in origin, 4 were lymphomatous and 4 were metastatic. Neurogenic tumours were most common in the posterior mediastinum consisting of 6 cases. 2 vascular lesions were seen, 1 of aortic aneurysm and 1 aortic dissection. The diagnostic accuracy of MDCT was $93 \%$ compared to histopathological results. Computed tomography (CT) plays a major role in evaluating mediastinal masses by virtue of its excellent multiplanar reconstruction capabilities and demonstration of exact anatomic relationships. However, in many situations, histopathological examination is needed to know the exact tissue of origin and for further management.

\section{CONCLUSIONS}

We conclude that $\mathrm{CT}$ has a major role in evaluating mediastinal masses regarding location, extent and tissue characterization. It can display certain features pathognomic for particular masses thus obviates the need for invasive procedures.

\section{KEY WORDS}

Mediastinal Lesions, MDCT, Imaging Modality, Histopathology
Corresponding Author:

Dr. Tanuja Sharma,

PG Girls Hostel No 2,

Rohilkhand Medical College and Hospital

Bareilly, Uttar Pradesh, India.

E-mail: sharmatanuja54@gmail.com

DOI: $10.14260 / \mathrm{jemds} / 2021 / 616$

How to Cite This Article:

Kumar M, Sharma T, Jain $M$, et al. Computed tomographic evaluation of mediastinal masses - an experience at a tertiary care centre in Bareilly, India. J Evolution Med Dent Sci 2021;10(35): 3017-3023, DOI:

10.14260/jemds/2021/616

Submission 25-03-2021,

Peer Review 29-05-2021,

Acceptance 05-06-2021,

Published 30-08-2021.

Copyright (c) 2021 Manish Kumar et al.. This is an open access article distributed under Creative Commons Attribution License [Attribution 4.0 International (CC BY 4.0)] 


\section{BACKGROUND}

Mediastinal lesions are one of the commonest intra-thoracic presentations in day to day radiology practice. Chest radiography is usually the first imaging investigation done in patients with mediastinal diseases. Various mediastinal reflections and lines are formed by the interface between the point of contact of soft tissue density of mediastinal structures and lungs. Lines such as anterior and posterior para-spinal lines, junctional lines, azygoesophageal lines and para-tracheal lines are normally seen on radiographs. Distortions in these reflections and lines give the clue of mediastinal masses. Various sign lines like hilum overlay, hilum convergence, silhouette sign, cervicothoracic sign, thoracoabdominal sign can also suggest the presence of mediastinal masses. Hilum overlay sign differentiates an opacity due to an enlarged heart or in the middle mediastinum from mass in the anterior mediastinum. If pulmonary hilum is seen within the confines of the opacity, then the opacity is due to the anterior/ posterior mediastinal mass and not in the middle mediastinum. Hilum convergence sign differentiates an opacity due to the lesion in the middle mediastinum or due to an enlarged pulmonary artery itself. If the pulmonary artery is seen converging towards/ lateral to the opacity and not towards the heart then the opacity is due to an enlarged pulmonary artery. While if pulmonary hilum is seen converging towards the heart and not towards/ lateral to the opacity, and the pulmonary hilum lies medial to the opacity, then that opacity is due to the enlarged middle mediastinal mass. Cervicothoracic sign - Cephalic border of the anterior mediastinum ends at the level of clavicles while posterior mediastinum extends higher up posteriorly. Therefore, if the opacity can be outlined well above the clavicle, then the mass lies in the posterior mediastinum.

Thoracoabdominal sign states that if opacity is seen extending down in the abdomen then the opacity is due to a lesion in the posterior mediastinum. The reason for this is that the posterior mediastinum is continuous below the diaphragm in the retro-crural area. Thoracoabdominal sign is positive in aneurysms and posterior mediastinal lesions. Multidetector computed tomography is done to obtain details of the anatomy and the nature of the lesion (fat, fluid, calcification etc.) and to narrow as well in reaching a diagnosis. Relations to the vital structures in the vicinity are identified. The compartmental approach is used to simplify the evaluation of mediastinal masses. ITMIG classification system is used most commonly. ${ }^{1}$ Other system for classification includes Felsons's, Anatomists, Heitzman classification systems. Felson method of division is based on the structures on the lateral chest radiograph. The line dividing the anterior and middle mediastinum passes from the diaphragm to the thoracic inlet al.ong the back of the heart and anterior to the trachea. The imaginary line connecting the points $1 \mathrm{~cm}$ posterior to the anterior margins of thoracic vertebral bodies divides the middle from the posterior mediastinum. The heart is therefore included in the anterior mediastinum according to Felson's classification while in the middle mediastinum according to the most commonly used ITMIG classification system. MDCT, therefore, plays a crucial role in staging the disease process, predicting prognosis and planning the treatment of the ongoing disease process. However histopathological evaluation is needed in many lesions to know the tissue of origin.

\section{METHODS}

This is a single centre prospective study done in the Department of Radiodiagnosis, Rohilkhand Medical College and Hospital, Bareilly for a span of one year from November 2018 to October 2019 and included 51 patients. Convenient sampling was done.

\section{Inclusion Criteria}

- Patients of both sexes, of all age groups clinically suspected to have mediastinal masses.

- Chest radiograph suggesting mediastinal widening or suggesting features of mediastinal masses.

- Incidentally detected patients with mediastinal mass for other indications.

\section{Exclusion Criteria}

- History of hypersensitivity to the contrast agent

- eGFR $<40 \mathrm{ml} / \mathrm{kg}$ body weight.

- Cardiac causes of mediastinal abnormalities.

- Pregnant women.

\section{Procedure}

Contrast-enhanced CT of the thorax was done using the following protocol. Patients were kept nil per oral for 4 hours before the scan. After explaining the procedure and taking consent, helical CT was done in supine breath-hold position using pitch of $<1$ from the thoracic inlet till the level of suprarenal glands. The rotation time was 2 seconds. Table feed/ interval was $10 \mathrm{~mm} /$ rotation. In all patients, plain scans were followed by contrast scans. Omnipaque (iohexol 350 $\mathrm{mg} / \mathrm{ml}$ ) was used as contrast agent in a dose of $1-2 \mathrm{ml} / \mathrm{kg}$. Post-processing techniques were employed for image interpretation. CT guided transthoracic needle biopsy/ FNAC was done for pathological correlation. Anterior parasternal or posterior para-vertebral approaches were used. Preferably direct mediastinal approach was used over the transpulmonary approach to avoid pneumothorax. Large bore 18 gauge semi-automatic core biopsy needle was taken and 2 - 3 tissue samples were taken from the target lesion under CT guidance. For FNAC, a 21/22 G spinal needle was used.

\section{Statistical Analysis}

The data was entered in an excel sheet and reported with SSPS version 23.0. The frequency was depicted in the form of tables as detailed below.

\section{RESULTS}

In the study comprising of 51 cases, the age group showing a maximum number of mediastinal masses was from $41-50$ 
years, comprising of 12 cases (23.5\%) followed by $11-20$ years age group which had 9 cases $(17.6 \%)$.

In our study, 33 cases (64.70\%) were males and 18 cases (35.29\%) were females. In our study, anterior mediastinum consisted of a maximum number of cases, consisting of 19 cases $(37.26 \%)$ followed by middle mediastinum with 16 cases $(31.37 \%)$ and anterior-posterior with 16 cases $(31.37$ $\%)$.

\begin{tabular}{|c|c|c|c|c|c|c|c|c|}
\hline 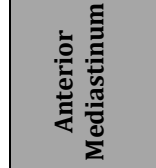 & $\frac{\bar{d}}{\bar{z}}$ & 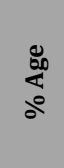 & 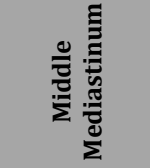 & 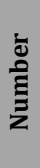 & 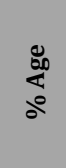 & 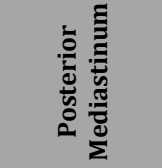 & $\frac{\dot{\bar{\Xi}}}{\frac{\mathrm{E}}{\mathbf{z}}}$ & $\begin{array}{l}\stackrel{8}{\infty} \\
\substack{0 \\
0}\end{array}$ \\
\hline Thymoma & 5 & 26.5 & $\begin{array}{l}\text { Carcinoma } \\
\text { esophagus }\end{array}$ & 4 & 25 & $\begin{array}{c}\mathrm{PV} \text { metastatic } \\
\text { mass }\end{array}$ & 1 & 6.25 \\
\hline Thymolipoma & 1 & 5.2 & Hilar mass & 3 & 18.75 & $\begin{array}{l}\text { TB LN mass \& } \\
\text { collection }\end{array}$ & 1 & 6.25 \\
\hline $\begin{array}{c}\text { Thymic } \\
\text { carcinoma }\end{array}$ & 1 & 5.2 & $\begin{array}{l}\text { Metastatic LN } \\
\text { mass }\end{array}$ & 3 & 18.75 & $\begin{array}{l}\text { Metatatic LN } \\
\text { mass }\end{array}$ & 1 & 6.25 \\
\hline $\begin{array}{c}\text { Aortic } \\
\text { dissection }\end{array}$ & 1 & 5.2 & $\begin{array}{l}\text { TB lymph } \\
\text { nodal mass }\end{array}$ & 2 & 12.5 & Schwannoma & 2 & 12.5 \\
\hline $\begin{array}{l}\text { Aortic } \\
\text { aneurysm }\end{array}$ & 1 & 5.2 & $\begin{array}{l}\text { Bronchogenic } \\
\text { cyst }\end{array}$ & 2 & 12.5 & Hiatus hernia & 1 & 6.25 \\
\hline $\begin{array}{l}\text { Thyroid } \\
\text { masses }\end{array}$ & 2 & 10.8 & $\begin{array}{c}\text { Metastatic } \\
\text { deposit }\end{array}$ & 2 & 12.5 & $\begin{array}{c}\text { Neurenteric } \\
\text { cyst }\end{array}$ & 3 & 18.75 \\
\hline $\begin{array}{l}\text { Germ cell } \\
\text { tumour }\end{array}$ & 3 & 15.9 & & & & Neuroblastoma & 3 & 18.75 \\
\hline Lymphoma & 4 & 21 & & & & TB collection & 2 & 12.5 \\
\hline TB LN Mass & 1 & 5.2 & & & & $\begin{array}{l}\text { Neurofibroma } \\
\text { Pancreatic } \\
\text { collection }\end{array}$ & 1 & 6.25 \\
\hline
\end{tabular}

Histopathological examination was done in 46 patients. In 2 patients with bronchogenic cysts, transbronchial aspiration of fluid cytology was done. Cases of pancreatic collection extending into the posterior mediastinum, hiatus hernia, aortic aneurysm and aortic dissection were not assessed histopathologically.

1 patient with a neurenteric cyst was very sick therefore could not be histologically assessed, diagnosis was made based on typical CT features in this patient. 3 reports were inconclusive, 43 patients (91.48\%) showed findings similar to that of radiological diagnosis. 1 patient who was diagnosed to be schwannoma on CT, showed neurofibroma on histopathology.

4 cases presented as mediastinal emergencies. One patient presented with aortic dissection involving aortic root, trunk, arch and ascending and descending aorta were seen. One patient had acute necrotising pancreatitis with a collection extending into the posterior mediastinum. 2 cases of SVC obstruction were seen and one was due to lymphoma and the other due to a malignant germ cell tumour.

A sensitivity of $97 \%$ and a positive predictive value of $91.3 \%$ was seen for evaluation of mediastinal masses keeping histopathology as the gold standard.

\begin{tabular}{|c|c|c|c|c|}
\hline & CT Diagnosis & $\begin{array}{l}\text { No. of } \\
\text { Cases }\end{array}$ & $\begin{array}{l}\text { HPE (CT-guided/ } \\
\text { Excisional/ } \\
\text { Transbronchial) }\end{array}$ & $\begin{array}{c}\text { Similarity } \\
\text { in } \\
\text { Diagnosis }\end{array}$ \\
\hline \multirow{9}{*}{$\begin{array}{c}\text { Anterior } \\
\text { mediastinum }\end{array}$} & Thymoma & 5 & 5 (1 report inconclusive) & 4 \\
\hline & Thymolipoma & 1 & 1 & 1 \\
\hline & Thymic carcinoma & 1 & 1 & 1 \\
\hline & Aortic dissection & 1 & 0 & \\
\hline & Aortic aneurysm & 1 & 0 & \\
\hline & $\begin{array}{l}\text { Mediastinal thyroid } \\
\text { masses }\end{array}$ & 2 & 2 & 2 \\
\hline & Germ cell tumours & 3 & 3 & 3 \\
\hline & Lymphoma & 4 & 4 & 4 \\
\hline & TB LN mass & 1 & 1 & 1 \\
\hline \multirow{6}{*}{$\begin{array}{c}\text { Middle } \\
\text { mediastinum }\end{array}$} & Ca esophagus & 4 & 4 & 4 \\
\hline & $\begin{array}{l}\text { HM infilterating } \\
\text { mediastinum }\end{array}$ & 3 & 3 & 3 \\
\hline & Metastatic LN mass & 3 & 3 (1 report inconclusive) & 2 \\
\hline & Bronchogenic cyst & 2 & 2 & 2 \\
\hline & Metastatic deposit & 2 & 2 (report inconclusive) & 2 \\
\hline & TB LN mass & 2 & 2 & 0 \\
\hline \multirow{10}{*}{$\begin{array}{l}\text { Posterior } \\
\text { mediastinum }\end{array}$} & PV metastatic mass & 1 & 1 & 1 \\
\hline & TB LN mass + collection & 1 & 1 & 1 \\
\hline & Metastatic LN mass & 1 & 1 & 1 \\
\hline & Schwannoma & 3 & 3 & 2 \\
\hline & Hiatus hernia & 1 & 0 & \\
\hline & Neurenteric cyst & 3 & 2 & 2 \\
\hline & Neuroblastoma & 3 & 3 & 3 \\
\hline & TB collection & 2 & 2 & 3 \\
\hline & Neurofibroma & 0 & $\begin{array}{c}\text { 1(1 case diagnosed on } \\
\text { HP) }\end{array}$ & 0 \\
\hline & Pancreatic collection & 1 & 0 & \\
\hline Table & . Histopathological & orr & tion in Mediastinal & sions \\
\hline
\end{tabular}
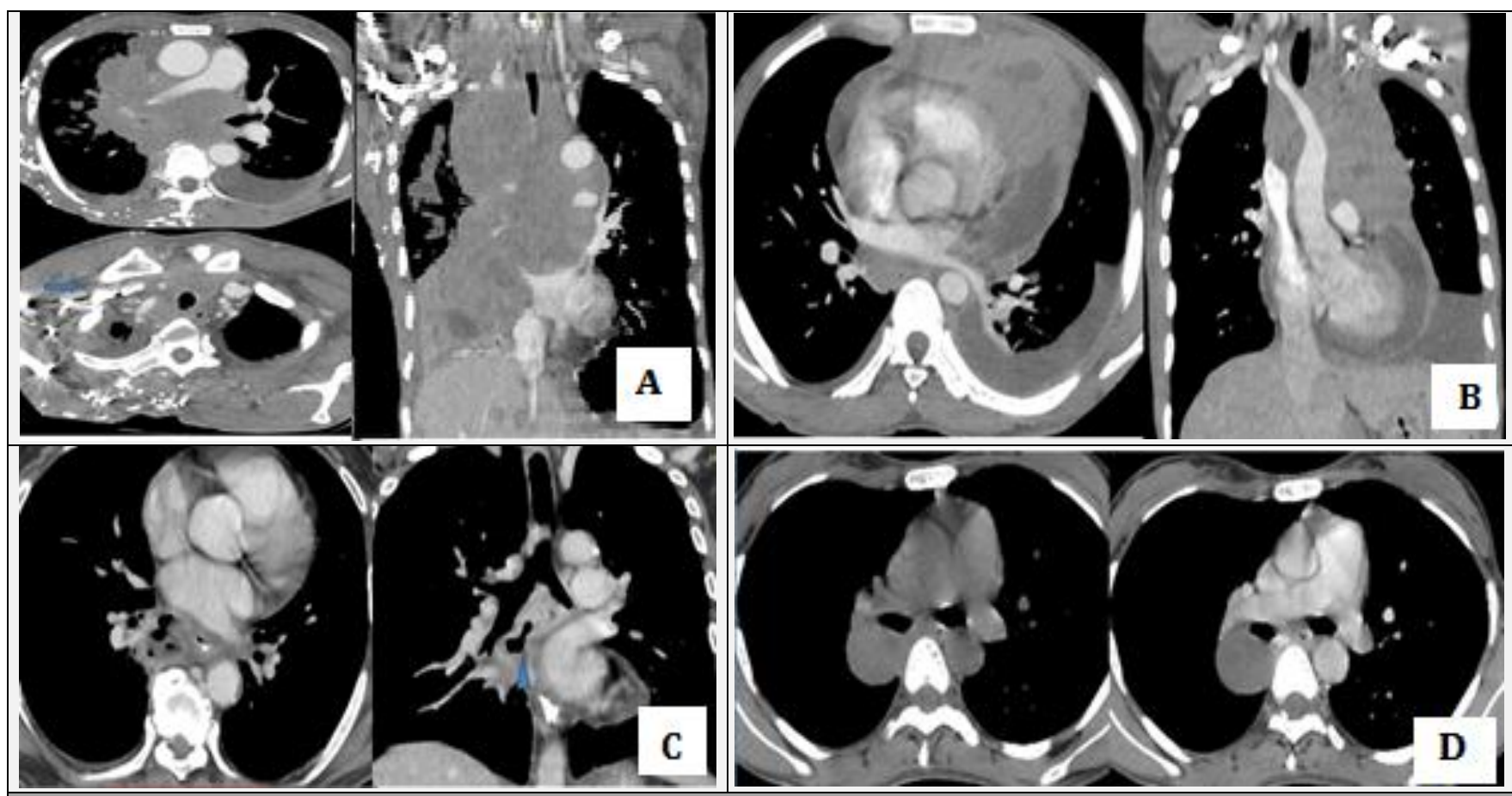

Figure 1 (a)- Lymphoma, Figure (b) - Germ Cell Tumour, Figure (c)- Esophagus Carcinoma with Periesophageal Abscess and Sealed Pneumomediastinum, Figure (d)-Bronchogenic Cyst 
Figure 1 (a) A large enhancing mediastinal mass (precontrast HU-36, post-contrast HU-47) extending from thoracic inlet till right middle lobe, abutting arch of aorta, pulmonary trunk and causing narrowing of the right main pulmonary artery causing the collapse of right middle lobe and lower lobe. Thrombosis of right subclavian artery (arrow), internal jugular vein (IJV) and superior vena cava (SVC), demonstrated in figure 1(a).

Figure (b) Large heterogeneously enhancing mass (precontrast HU-29, post-contrast HU-48) in anterior \& superior mediastinum showing areas of necrosis \& fat density (HU - 15) extending from isthmus of the thyroid to diaphragm, encasing arch of the aorta and its major branches, pulmonary trunk, narrowing left main pulmonary artery. There is infiltration of the parietal pericardium, anterior chest wall and intercostal vessels, superior part of the right ventricle and right ventricular outflow tract (depicted in figure b).

Figure (c) Irregular enhancing (pre-contrast HU- 23, postcontrast HU-36) mural thickening of the oesophagal wall with peripherally enhancing lesion with multiple air foci in the right peri-oesophagal region. A curvilinear blind tract with air density (HU- -986) (arrow) is seen extending from this lesion to carina suggestive of loculated/ sealed pneumomediastinum. Figure (d) Oval cystic lesion (pre-contrast HU31 , post-contrast HU-32) abutting right main bronchus.

Figure2 (E) Dilatation and intimal flap in the aortic root, arch of aorta, left subclavian artery and descending aorta till origin of the renal artery. The flap is flat \& vertically oriented dividing the aorta into right-sided wider false lumen \& narrower true left lumen. This is classified as Stanford type A and DeBakey type I classification type aortic dissection.

Figure (F) Asymmetric irregular concentric mural thickening of the oesophagal wall with loss of fat planes with the trachea. Fistulous communication between mass \& tracheal lumen as well as the adjoining lung abscess was seen. The patient was given oral contrast which was seen lining the fistula and reaching abscess in consolidation in the adjacent lung.
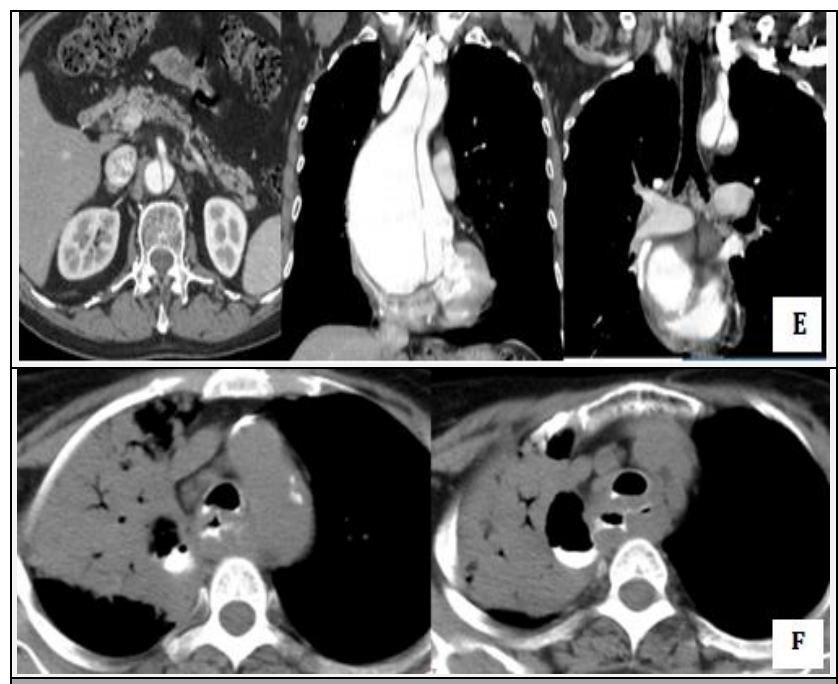

Figure2: (e) Aortic Dissection, Figure (f) Ca Esophagus with Tracheoesophageal Fistula and Esophagopleural/ Parenchymal Fistula

Figure 3(G) Large lobulated ill-defined enhancing mediastinal based mass with necrotic areas seen extending through the diaphragmatic foramen into retroperitoneum pushing descending aorta, left supra-renal and left kidney anteriorly. It was infiltrating into the anterior chest wall and pericardium as demonstrated in figure 7.

Figure $(\mathrm{H})$ Large cystic lesion extending from intra-spinal region to posterior and middle mediastinum from C7, D1 block vertebrae up to L1 level. Fat density (HU - -11) was seen in contents. The patient also had marked scoliosis and elevated right hemidiaphragm with right kidney seen just under the diaphragm. Figure (I) In a patient with pancreatitis, collection seen in the pancreatic head was seen extending into the posterior mediastinum.

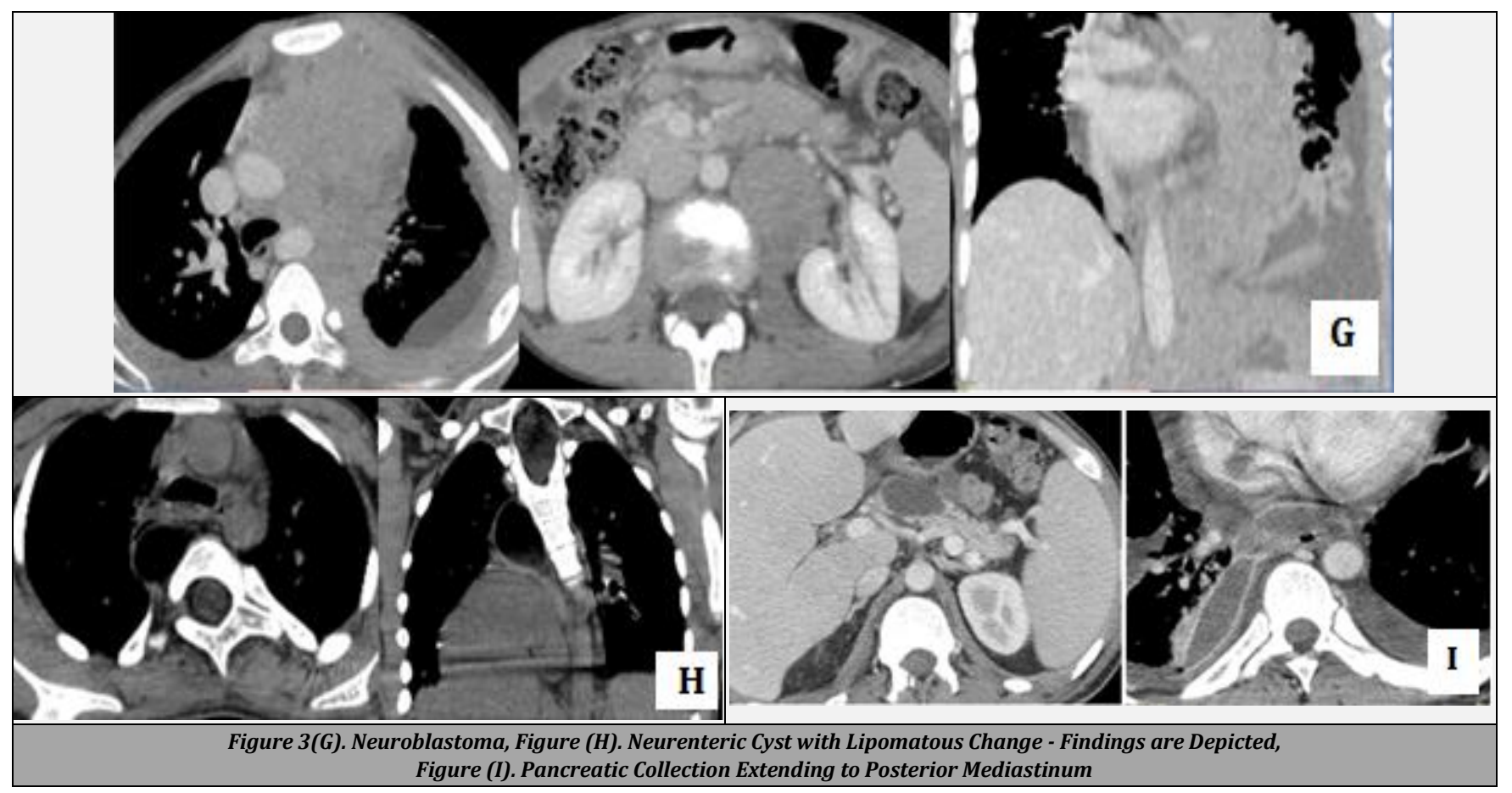




\section{DISCUSSION}

In our study of 51 cases, patients who showed abnormal radiographs or those having suspicion of mediastinal diseases underwent CT evaluation. The CT features were then analysed.

\begin{tabular}{|ccc|c|}
\hline & Pandey et al.. & $\begin{array}{c}\text { Juanpere et } \\
\text { al.. }\end{array}$ & Our Study \\
Anterior mediastinum & $33.3 \%$ & $50 \%$ & $19(37.26 \%)$ \\
Middle mediastinum & $31.6 \%$ & MM+PM - 50\% & $16(31.37 \%)$ \\
Posterior mediastinum & $18.3 \%$-posterior & $16(31.37 \%)$ \\
\hline \multicolumn{2}{|c|}{$16.6 \%$-multicompartment } \\
\hline \multicolumn{2}{|c|}{ Table 3. Compartmental Distribution of Mediastinal Masses } \\
\hline
\end{tabular}

In our study, the majority of mediastinal masses were in the anterior mediastinum (37.26\%), followed by middle mediastinum (31.37\%) and posterior mediastinum (31.37 $\%$ ). Results were close to study by Pandey et al. ${ }^{18}$ who stated that anterior mediastinal masses were the most common of all mediastinal masses.

In the anterior mediastinum, thymomas were most common constituting 5 cases $(26.3 \%)$ out of 19 . Thymomas were followed by lymphomas (21\%). The findings are similar to the study conducted by carter et al. which stated that thymomas are the most common masses in pre-vascular compartment. ${ }^{1}$ In our study, thymic carcinoma constituted 1 case, $14.28 \%$ of tumours of thymic origin. Study by Juanpere et al. ${ }^{2}$ which stated that thymic carcinomas are $20 \%$ of all thymic origin tumors. 1 case, (5.26\%) of thymolipoma was also seen. Results are close to study by Juanpere et al. which stated that thymolipomas are 2 - $9 \%$ of neoplasms of thymic origin. Carter et al. also stated that thymolipomas constitute less than $5 \%$ of all anterior mediastinal masses.

In our study $75 \%$ of lymphomas were seen in children, results are similar to study by Leschied JR et al. ${ }^{3}$ who also stated that lymphomas are the most common anterior mediastinal masses in children. 4 patients had lymphoma in our study. 2 patients had associated cervical LAP, 1 had associated abdominal LAP and 3 had splenomegaly. 1 patient with lymphoma had atypical features and showed multiple thrombi in IJV and right subclavian vein, compression of IVC and involvement of lung and pleural deposits. In our study, germ cell tumors constituted 3 cases, $15.9 \%$ of all anterior mediastinal masses in adults. Our findings are similar to findings of Juanpere et al. $^{2}$ who stated that germ cell tumors constitute $10-15 \%$ of all anterior mediastinal masses.

In our study, 2 patients had retrosternal or mediastinal goiters showing cystic areas \& calcification. Study by Juanpere et al. ${ }^{2}$ also stated that mediastinal goiters were enhancing masses that showed areas of calcification and cystic change. Bronchogenic cyst was seen at carina on right side. Study by Carter et al. ${ }^{1}$ also stated that carina was the most common site for bronchogenic cysts. ${ }^{1}$

The posterior mediastinum neurogenic tumors formed the maximum number of cases consisting 6 cases (37.5\%) out of 16 posterior mediastinal masses. Carter et al. ${ }^{1}$ also stated that neurogenic tumors are the most common para-vertebral masses. Splaying of ribs and scoliosis were seen in 1 patient with neurenteric cyst. The patient also had fat density as well as solid density in the contents herniating from spinal canal. The patient had other associated anomalies like elevated right hemidiaphragm with right kidney just below the right hemidiaphragm.

All neuroblastomas were seen in 1st and 2nd decade. In our study all 3 cases of neurenteric cyst were seen in the posterior mediastinum. Our study had 2 cases of hiatal hernia. Both the cases were sliding type. Study by Occhipinti et al. ${ }^{4}$ stated that $95 \%$ of cases of hiatal hernia were sliding type of hiatal hernia.

Tubercular lesions were found in all 3 compartments in the form of lymph nodal masses and pre and para-vertebral abscesses with associated vertebral body destruction and spondylodiscitis. Tubercular lymph nodes have low density centre surrounded by peripheral rim, that shows contrast enhancement. Peripheral rim sign is however not specific and can also be seen in metastatic lesions, histoplasma and lymphoma lesions as well.

Out of all mediastinal masses, 7 cases had tumors of thymic origin (13.7\%). Metastasis was the overall leading diagnosis in our study. Differentiating rim enhancing lesions between tubercular and necrotic metastatic masses was sometimes difficult using CT alone.

\section{Vascular Lesions}

CT is capable of detecting lesions of aorta as well as identifying aneurysms that are stable thus only require follow up and aneurysms that are unstable and needle urgent operative intervention thus aid in management. In our study 1 patient had aortic dissection involving aortic root, ascending, arch of aorta and descending aorta till the origin of renal arteries. 1 case of aortic aneurysm was also seen. Study by Occihipinti $\mathrm{M}$ et al. ${ }^{4}$ stated that CT could well differentiate between stable and unstable aortic lesions and determining the type of aortic dissection.

\section{Criterias Used for Differentiating Benign versus Malignant Lesions Were}

Maintained fat planes with the adjacent organs, well defined borders, non significant enhancement on post contrast study. While features to favour malignancy were loss of fat planes with adjacent organs, presence of pleural/ pericardial/ lung deposits and invasion/ encasement/ infilteration of adjacent structures/vessels.

\section{The Salient Features of Common Mediastinal Masses are Described below \\ Bronchogenic Cysts}

Typical location - carina, may occur anywhere in other mediastinum and intra-pulmonary location. They occur due to abnormal budding in primitive foregut that forms tracheobronchial tree. Rupture of cyst and malignant transformation are rare complications that can occur in all cystic lesions of mediastinum including bronchogenic, esophageal duplication and neurogenic cysts. Imaging does not always differentiate between the type of cyst and histology may be required for their diagnosis most of the times. ${ }^{1,5}$ 


\section{Thoracic aortic aneurysm}

Permanent dilatation of aorta by atleast $50 \%$ diameter. Normal diameter of mid-descending aorta is $2.39-2.98 \mathrm{~cm}$ and $2.45-2.64 \mathrm{~cm}$ in males and females respectively. CT helps in differentiating unstable aneurysms (require emergent intervention) and stable aneurysms (can be managed conservatively). Unstable aneurysms show rapid enlargment and signs of rupture like high attenuating crescent within the aortic wall reflecting intramural hematoma, focal discontinuity in intimal calcification, eccentric shape of aorta and a draped aorta or the one with indistinct margins between posterior aortic wall from adjacent vertebral body. Peri-aortic/cardiac soft tissue hematoma and contrast blush of active extravasation at site of rupture can also be seen on CT. Patients with maximum aortic diameter of $6-6.5 \mathrm{~cm}$ and enlarging at $10-12 \mathrm{~mm}$ per year are candidates for surgery. Endovascular treatment includes stent implantation. $6,7,8$

\section{Aortic Dissection}

It results from tear in intimal layer that allows inflow of blood towards tunica media creating false lumen. According to Stanford classification, type A includes dissection of ascending aorta, type B includes descending aorta. Type A requires urgent management. CECT determines the type of dissection, demonstrates intimal flap, entry and re-entery points, signs of rupture, organ perfusion and extension of false lumen into valves. Triple rule-out CT protocol is developed to assess aortic dissection, pulmonary embolism and acute coronary syndromes. ${ }^{9,10,11}$

Esophageal neoplasms can be benign and malignant. Squamous cell carcinoma (SCC) and adenocarcinoma are malignant neoplasms of oesophagus. CT demonstrates irregular enhancing concentric mural thickening in an esophageal neoplasm. It is capable of assessing local as well as distant metastasis. Fistulous tract with adjoining trachea as well as lung parenchyma can be seen. Oral and intravenous contrast are needed for visualisation of lumen of esophagus. Most SCC are located in middle third and adenocarcinoma in the lower third. Endoscopy is capable of visualising even small esophageal lesions. Lymph nodal staging is limitation of CT. Endoscopic ultrasound aspiration helps in assessment of regional lymph nodes. FDG-PET improves accuracy of staging distant diseases as well as in predicting response to neoadjuvant therapy. ${ }^{6}$

\section{Para-Vertebral Compartment Lesions}

Neurogenic tumors including neuroblastoma, ganglioneuroma and ganglioneuroblastomas, schwannomas, neurofibromas, metastatic masses, paravertebral abscess due to spondylodiscites and lymph nodal enlargement, extramedullary haematopoiesis. ${ }^{1}$ These frequently show intra-spinal extension and vertebral body defects. ${ }^{1}$

\section{Neuroblastomas}

MC location is adrenal gland followed by retroperitoneum and posterior mediastinum. Neuroblastomas are invasive heterogeneously enhancing tumors that tend to encase vessels and spread through the neural foramina into spinal canal. 8,12

\section{Meningocele}

These are anomalous herniation of leptomeninges through intervertebral foramen or VB defect. The herniated content may show fat density or tissue of any cell lineage. Differentiation of neurenteric cysts and neurogenic neoplasms from meningoceles is often difficult, however association of neurogenic tumors with neurofibromatosis may point towards diagnosis. 8,12,13

\section{Tuberculosis}

Wide spectrum of lesions including lymph nodal masses, abscesses and spondylodiscites. Differentiation between infection due to tuberculosis or other pyogenic bacteriae can be done using CT. TB is characterised by involvement of posterior elements and pre and para-vertebral soft tissue components out of proportion to bony destruction and IV disc space narrowing. Calcification without new bone formation and sclerosis also strongly point towards tuberculosis rather than spondylodiscites due to other bacterias. ${ }^{12,14}$

Hiatal Hernia refers to herniation of abdominal contents into the chest. Two types of hiatal hernias are sliding and para-esophageal hernia. In sliding hernia gastro-esophageal junction migrates above the diaphragm $(>2 \mathrm{~cm}$ above the hiatus, hiatus $>3 \mathrm{~cm}$ in diameter) and is often associated with GERD. In para-esophageal/ rolling hernia, stomach herniates without any movement of GE junction. Para-esophageal hernias may present acutely with obstruction due to gastric volvulus causing bleeding, strangulation and even perforation of stomach. Rupture and stretching of phrenico-esophageal ligament is a common cause for hiatal hernias. ${ }^{7}$

\section{CONCLUSIONS}

We conclude that computed tomography has a major role in evaluating mediastinal masses regarding location, extent and tissue characterization. It can display certain features pathognomic for particular masses thus obviates the need for invasive procedures. Lesser cost, wider availability and lesser time of acquisition makes it preferable to MRI for evaluation of mediastinal lesions particularly in the Indian context. However, in a large proportion of cases, histopathological evaluation must complement the CT diagnosis.

Computed tomography has limitations in detecting complex cystic lesions and posterior mediastinal lesions and for differentiating thymic hyperplasia from malignant thymic masses in which magnetic resonance imaging is more sensitive. PET-CT also is more capable of detecting and staging malignant lesions with greater sensitivity and specificity.

Data sharing statement provided by the authors is available with the full text of this article at jemds.com.

Financial or other competing interests: None.

Disclosure forms provided by the authors are available with the full text of this article at jemds.com.

\section{REFERENCES}

[1] Carter BW, Benveniste MF, Madan R, et al.. ITMIG classification of mediastinal compartments and 
multidisciplinary approach to mediastinal masses. Radiographics 2017;37(2):413-36.

[2] Juanpere $S$, Cañete $N$, Ortuño $P$, et al.. A diagnostic approach to the mediastinal masses. Insights Imaging 2013;4(1):29-52.

[3] Leschied JR, Sanchez R, Mahani MG. Imaging evaluation of pediatric mediastinal masses: pearls and pitfalls. Applied Radiology 2017;46(11):8-20.

[4] Occhipinti M, Heidinger BH, Franquet E, et al.. Imaging the posterior mediastinum: a multimodality approach. Diagnostic and Interventional Radiology 2015;21(4):293-306.

[5] Jeung MY, Gasser B, Gangi A, et al.. Imaging of cystic masses of the mediastinum. RadioGraphics 2002;22(Spec Issue):S79-S93.

[6] Lewis RB, Mehrotra AK, Rodriguez P, et al.. Esophageal neoplasms: radiologic - pathologic correlation. RadioGraphics 2013;33(4):1083-108.

[7] Andrici J, Tio M, Cox MR, et al.. Hiatal hernia and the risk of Barrett's esophagus. J Gastroenterol Hepatol 2013;28(3):415-31.

[8] Kumar R, Jain R, Rao KM, et al.. Intraspinal neurenteric cysts-report of three paediatric cases. Child's Nervous System 2001;17(10):584-8.
[9] Hiratzka LF, Bakris GL, Beckman JA, et al.. 2010 ACCF/AHA/AATS/ACR/ASA/SCA/SCAI/SIR/STS/SVM Guidelines for the diagnosis and management of patients with thoracic aortic disease: executive summary. Journal of the American College of Cardiology 2010;55(14):1509-44.

[10] Chiu KWH, Lakshminarayan R, Ettles DF. Acute aortic syndrome: CT findings. Clinical Radiology 2013;68(7):741-8.

[11] Upadhye S, Schiff K. Acute aortic dissection in the emergency department:diagnostic challenges and evidence-based management. Emergency Medicine Clinics North Am 2012;30(2):307-27.

[12] Kawashima A, Fishman EK, Kuhlman JE, et al.. CT of posterior mediastinal masses. Radiographics 1991;11(6):1045-67.

[13] Strollo DC, Rosado-de-Christenson ML, Jett JR. Primary mediastinal tumors. II. Tumors of the middle and posterior mediastinum. Chest 1997;112(5):1344-57.

[14] Moore SL, Rafii M. Imaging of musculoskeletal and spinal tuberculosis. Radiologic Clinics of North America 2001;39(2):329-42. 